\title{
Transition to practice, lessons learned: Academic general thoracic surgery
}

\author{
Elizabeth A. David, MD, ${ }^{\mathrm{a}, \mathrm{b}}$ and Basil S. Nasir, $\mathrm{MBBCh}^{\mathrm{c}}$
}

\footnotetext{
From the a Section of General Thoracic Surgery, Department of Surgery, University of California Davis Medical Center, Sacramento, Calif; ' ${ }^{\text {David }}$ Grant Medical Center, Heart, Lung and Vascular Center, Travis Air Force Base, Calif; and ${ }^{c}$ Vancouver General Hospital, University of British Columbia, Vancouver, British Columbia, Canada.

Disclosures: Authors have nothing to disclose with regard to commercial support

Received for publication July 9, 2015; revisions received Oct 28, 2015; accepted for publication Dec 13, 2015; available ahead of print Jan 22, 2016.

Address for reprints: Elizabeth A. David, MD, Section of General Thoracic Surgery, 2221 Stockton Blvd, Rm 2121, Sacramento, CA 95817 (E-mail: elizabethadavid@gmail.com).

J Thorac Cardiovasc Surg 2016;151:920-4

0022-5223/\$0.00

Published by Elsevier Inc. on behalf of The American Association for Thoracic Surgery

http://dx.doi.org/10.1016/j.jtcvs.2015.12.020
}

Those of us who have chosen to pursue academic general thoracic surgery have accepted the additional challenge of incorporating high-quality research and surgical education into our operative careers. The core values of the Association for Academic Surgery include collaboration, scientific excellence, promotion, diversity and inclusivity, innovation, and mentorship. ${ }^{1}$ As young academic thoracic surgeons, we are challenged with balancing these values and establishing our operative career.

As young faculty members, our first priority must be to establish ourselves as excellent operative surgeons. We need to achieve high-quality surgical outcomes and prove ourselves as future surgical leaders. We cannot completely focus inward as new academic surgeons, however; we have to find a way to balance educating trainees and nurturing relationships with other physicians to build our practices and careers.

Establishing formalized career goals can help a young surgeon determine where he or she wants to be and how to achieve those goals, which should include clinical, research, education, and personal aspects. It is helpful to refer to these goals frequently to remind yourself of where you were planning to go and check whether you are actually on the right path. The goals will change with time, but this can also be a great way to assess progress and achieve some sense of accomplishment along what can otherwise be a very hard road.

\section{ADAPTING TO A NEW OPERATING ROOM ENVIRONMENT}

The operating room (OR) is one of the most unique aspects of a surgeon's practice, and can be a source of stress and anxiety to new thoracic surgeons. Maintaining control of the culture in the OR is key to a surgeon's success. Although we have all "performed" cases as trainees, the focus there was mainly on the technical details. No matter how much autonomy you experienced during training, the

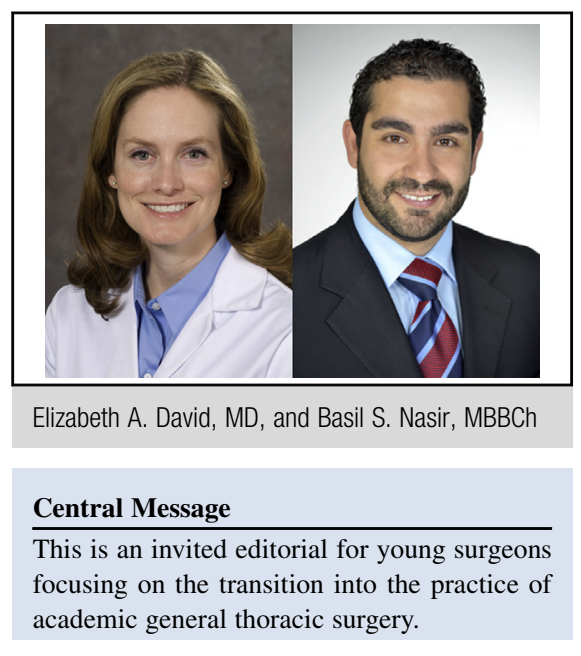

See Editorial Commentary page 924.

evolution from a supervised trainee to the attending surgeon can be daunting. There is more to a case than just the technical, operative details. There are the patient factors, the interactions with the operating room staff and the anesthesiologists, the organization of cases, the management of assistants, and in some cases, the ability to take a resident through a case.

In the beginning stage of your career, you may benefit from reviewing complex cases with a senior partner or mentor before the operative case to maximize operative success and minimize avoidable complications. It is also useful to keep an open mind during operative planning and procedures. Use your experienced team members in the beginning of your operative career. This is especially important for surgeons who change institutions between training and practice. The practice will be different, instruments will be different with different names, and so on. Although you should not completely change the way you have been trained, you also should not be too rigid. For example, if the self-retaining retractor that you prefer is not readily available, then perhaps the one that has been used by the group on similar cases would suffice-after all, it did work for them in their many years of practice. Some additional tips for adapting to a new OR environment are shown in Table 1.

\section{Dealing With Complications}

There is no greater anxiety than the anxiety that a surgeon experiences during a catastrophic intraoperative or postoperative complication, such as a pulmonary arterial 
TABLE 1. Tips for establishing a healthy environment in the OR

- Set yourself up for success in the OR. Avoid scheduling complex cases late in the day when adequate assistance may be in short supply.

- Schedule a mix of easy cases and hard cases in the same day, because you will be more physically and mentally fatigued by your OR days than you were as a trainee.

- Get to know your OR staff. Identify their level of experience, their familiarity with thoracic surgical cases, and any specific preferences they have. This is particularly important with veteran staff.

injury. Considerable training time is devoted to learning how to avoid such complications. Most of us will not have had an opportunity to deal with these complications frequently. The following are some suggestions for successfully navigating a major operative complication:

1. Get additional help. The first thing to do is call for help, preferably from a senior partner, but even if one is not available, any of your partners will be a great aid. Go into every case knowing who you will call if an intraoperative misadventure occurs.

2. Learn from your mistakes. The only way to avoid pulmonary artery injuries completely is to stop doing lobectomies. With each complication, there is always something to be learned. Perhaps it is how to avoid such a complication, how to better deal with it when it occurs, or how to improve communication with your team members. Morbidity and mortality conferences are very important, but they are no substitute for the individual reflection that should be done after complications occur.

3. Learn to move forward. Complications can have a significant impact on a surgeon's confidence. After a major pulmonary artery injury, it is normal to have anxiety during the next lobectomy. Reflecting on and discussing the case with your mentors and colleagues is helpful, but it is important to not let the events shake your confidence and paralyze your ability to function at a high level in the OR.

\section{BUILDING RELATIONSHIPS}

Just as in our training, relationships with mentors, colleagues, and other healthcare providers are critical to successful patient care and the practice of academic thoracic surgery. As recent graduates, it is important to maintain the relationships that were established during training with senior surgeons and educators, and also to embrace new mentors. Develop a list of people who you can call for the various scenarios that you encounter, whether complex operative cases, challenging resident interactions, or research struggles. Your friends from training will be invaluable to you as a young surgeon as resources to ask the questions that you are embarrassed to ask someone else, and also to celebrate your successes and reflect on failures. Remember, you can learn something from anyone. You will learn things you want to do again and some things that you never want to do again. The same will be true for your academic career. Discussing career options and plans with a few people is a great idea, because they will bring different perspectives to the decisions you are trying to make.

\section{Finding Mentors}

Do not fall into the trap of looking for one person to be your mentor. Rather, you will want to find an entire team. Look for people who are achieving something that you want. Do not be afraid to look outside academic general thoracic surgery for research and educational mentors. Talk with potential mentors and feel out the relationship, encourage the ones that seem fruitful and do not pursue the ones that do not seem high yield. Great mentors will hold you accountable to the goals you set; they will support you through failures and celebrate your successes.

Although the relationship between academic success and mentorship is well studied and undeniable, some young surgeons remain hesitant to seek mentorship. ${ }^{2-4}$ Finding great mentors is certainly challenging, but definitely worth the effort. Surgeons are frequently concerned about appearing weak; having mentors and using them is a sign of strength and wisdom.

\section{Learning to Be a Colleague}

Your relationship with referring physicians and colleagues is critical to academic success. Even in environments where there are no direct referrals, being a good surgical citizen and a physician on whom others can rely goes a long way. Find peers in other fields who may be struggling with similar academic issues and research pressures. These relationships can lead to friendships and collaborations, and may enhance your surgical practice. Similarly, your relationships with your midlevel providers, OR staff, and residents are critical to your success. These are the relationships that can drastically affect your quality of life; ability to juggle teaching, education, and surgery; and ability to develop a high-quality practice. Cultivate these relationships carefully and establish them in respectful ways.

\section{IDENTIFYING A NICHE}

In today's academic climate, there is increased emphasis on becoming an expert in a narrow clinical or academic domain. In some situations, this "niche" has been identified 
for us, by virtue of our training, but this is not always the case. Even if you identify a specialized area of interest, you should not disregard the importance of being able to perform "bread and butter" cases, considering that it may take several years to develop your niche, and doing so should not come at the price of developing confidence in other aspects of thoracic surgery.

\section{Selecting a Niche}

An ideal niche is a clinical problem that is rare enough that there are minimal specialists already in practice, but common enough that you likely will actually see it. Another way to establish an area of expertise is to focus on a technique not commonly performed in your region, such as minimally invasive esophagectomy, advanced endoscopic techniques, or robotic surgery. Your niche should be genuinely interesting to you, considering that the challenges to come may be frustrating. If your niche involves the creation of a new service line, make sure that you have the support of your mentors and departmental leadership before starting.

\section{Creating a Niche}

Embrace the idea that you are an expert about your niche. Educate the community; give grand rounds and other talks about your niche, and you will become acknowledged as the expert. Ask your senior partners to refer niche cases to you instead of tackling them themselves. If your niche involves a new technology or a case that has never been done in your institution, chose your patient very selectively to optimize your results. For example, if you are starting a peroral endoscopic myotomy program, your first case should not be a reoperative case with a sigmoid esophagus; rather, it should be a straightforward case where the risk of complications is low. Depending on the volume at your institution and your chosen niche, it may take several months before an optimal case is available; be patient.

Ensure adequate training in your chosen niche. If you have completed a specific fellowship in a specialized area, you most likely have met the requirements for performing niche procedures. You may decide to develop a niche in an area in which you have had little previous experience. This is an acceptable approach, but there is usually a well-defined pathway to achieving proficiency. For example, for surgeons who were not exposed to robotics in their training but choose to adopt robotics in their practice, video-based and simulator training sessions, as well as wet-lab and proctored cases, may be required before a hospital will approve robotics privileges. In the case of other niches, there is no outline, and you may have to devise your own outline using available resources. Use your mentors and input from your division chair to help you in creating the most effective means to achieving this proficiency so as to ensure success in your niche.

It is also important to be prepared to answer patients' tough questions about how much training and how many cases you have actually successfully completed. Be honest; do not exaggerate your level of experience. Emphasize the safety mechanisms that you have in place to ensure a successful procedure. If you have a proctor coming for the case, disclose that to the patient if asked, to reassure the patient that you are not experimenting on him or her.

As you are developing your niche and starting your career, you may encounter questions from colleagues and patients about your level of experience with these procedures. It is critical that you answer these questions honestly. Do not exaggerate your level of experience. Explain the training that you have had in the procedure as well as in related procedures. It is also a good idea to explain the safety measures that you have in place for your first few cases to optimize safety and procedural outcomes. When developing a new program, you may encounter patients who simply do not want to be part of the learning curve. You need to respect this. Do not prioritize your niche or new program over your patients.

Remember to remain considerate of competing specialists when developing your niche. Commonly selected niches are clinical problems that can be approached in different ways, and sometimes by different specialists. An example of this situation is advanced endoscopic techniques, where there may be some resistance from pulmonologists or gastroenterologists. Collaborative approaches are usually the best way to tackle these issues. We have developed a program along with these specialists, rather than independent of one another. We have seen this approach work well in the development of a nationwide practice for transcatheter aortic valve replacement in collaboration with cardiologists, and have chosen this approach to cultivate our advanced endoscopy practice. ${ }^{5}$

\section{DEVELOPING YOUR CAREER AS AN EDUCATOR AND SCIENTIST \\ Becoming a Surgical Educator}

Most of us survive surgical training with the help of our coresidents, and along the way we learn to teach the junior residents coming up the ranks behind us. Very few of us actually have formal training in surgical education, and yet those of us who have chosen academic thoracic surgery are immediately thrust into the role of educator. This can be an intimidating prospect to a junior faculty member who feels like he or she is still trying to figure how to run his or her own practice. Success in resident education requires that the new surgeon balance operative outcomes and resident training. How much can you let a resident do in the OR? The answer to that question will vary widely, but it is important to remember that your outcomes need to be 
your outcomes for the first few years. When considering the tasks that residents can perform in the OR, it is important to consider all of the downstream effects of any potential misadventures and make sure that you can get out of those scenarios. In cases where you decide to minimize active resident participation, it is important to maximize their involvement in the case on an academic level. Talk with them, make sure they understand the anatomy, and explain what you are doing, why you are doing it, and the misadventures that you are hoping to avoid. Break cases down into segments and inform the residents of which portions they will be allowed to do; for example, a junior fellow or resident may be allowed to dissect the inferior pulmonary ligament and pulmonary vein, after which you take over for the remainder of the dissection.

The clinic and rounds provide more time and a lower-pressure environment for teaching. Taking time to review radiographic images, cancer staging systems, and guidelines does not take much time or energy on your part but goes a long way with trainees. It is important to be conscious of how teaching is affecting your time management. To teach in the clinic, you may need to see some patients on your own, to give residents the time they need to evaluate a patient and review the case and prevent a 2-hour backup in your clinic.

The clinic can also be a challenge for teaching, considering that the learners may vary widely in experience level. Many medical students report feeling nervous and fearful of appearing incompetent during surgical rotations; it is your job as the surgeon to make them feel comfortable so that they will learn something on the rotation. ${ }^{6}$ Make sure you are teaching at the appropriate level for your learners by asking some questions to identify the level of their knowledge.

Teaching residents includes sharing not only operative skill and patient care knowledge, but also research skills. As a junior faculty member, it is unlikely that you will be in a position to give up large projects completely to residents as you are trying to establish your own research career; however, you can find ways to incorporate them into large projects with small contributions or can mentor them through smaller projects such as case series, book chapters, and surgical video presentations. It is important to remember that you are a mentor for your trainees, and that they will be learning from everything you do and how you take care of your patients. Familiarize yourself with the Accreditation Council for Graduate Medical Education milestones to which residents are held, so that you know what they are expected to learn and can make sure that it is covered on their rotations.

\section{Becoming a Surgeon Scientist}

Many surgeons who chose an academic career have spent dedicated time during training to gain the skills and knowledge needed to pursue a basic science or health services research career, but this is not mandatory. Identifying research goals and mentors is a critical component to the start of promising research career. As part of the process of creating goals, assess your own skillset honestly and determine where deficiencies may exist. Do not be afraid to seek formalized training needed; many institutions offer refresher statistics and research methodology courses designed for clinicians.

Depending on your contract and the resources of your department, there may be barriers to overcome for funding and research time. Do not be discouraged; your scientific mentors have likely struggled with the same issues. Set realistic goals and expectations for your productivity based on the resources actually available to you. Be careful about "protected time." It is very important to have dedicated time for research, but when you are trying to establish your career as a surgeon, your partners and referring doctors need to understand that you are a surgeon when your patients need a surgeon. Do not refuse to leave the lab when a patient is struggling.

Although frustrating for many of us, competing for research funding is a necessary part of a research career. Credibility and funding frequently go hand in hand, and many young researchers can be discouraged by the process that can often seem impossible to master. Rely on your mentors for assistance with the grant application process. Diversify your applications; apply for small and large grants simultaneously. Put energy into developing your research proposal the first time around, so that it can be reworked easily for many applications if necessary.

Academic general thoracic surgery is an exciting and rewarding career field that offers young surgeons the opportunity to influence the lives of our patients, surgical trainees, and colleagues even early in our careers. There is no one perfect career path or recipe that leads to success in academic general thoracic surgery. There are many pathways to success, and each academic thoracic surgeon needs to determine what success means individually. No two great surgeons have a similar life story and career history, but most great surgeons have a life outside of surgery. Do not lose sight of the things in your life that make you who you are besides a surgeon; find ways to balance your passion for academic thoracic surgery and your personal life. Like most great things in life, there will be hard work and frustrating aspects of the life of an academic general thoracic surgeon, but with patience and perseverance, and by surrounding yourself with other people who can support you, the rewards of your own successful academic practice are truly limitless.

\section{References}

1. Kao LS. Real world versus ivory tower: the challenge for academic surgery. J Surg Res. 2014;190:9-15. 
2. Rudnicki PA, Liang F, Prince NH, Lipsitz S, May JW Jr, Guo L. What made them successful: an introspective survey of AAPS members. Plast Reconstr Surg Glob Open. 2015;3:e327.

3. Lou X, Enter D, Sheen L, Adams K, Reed CE, McCarthy PM, et al. Sustained supervised practice on a coronary anastomosis simulator increases medical student interest in surgery, unsupervised practice does not. Ann Thorac Surg. 2013;95: 2057-63.
4. Upchurch GR Jr, Freischlag JA, Novicoff W, Early K, Turner PL, Zinner MJ, et al. Survey of the American College of Surgeons scholarship recipients: a story of generating academic leaders. J Am Coll Surg. 2015;220:1122-7.e3.

5. Sintek M, Zajarias A. Patient evaluation and selection for transcatheter aortic valve replacement: the heart team approach. Prog Cardiovasc Dis. 2014;56:572-82.

6. Stone JP, Charette JH, McPhalen DF, Temple-Oberle C. Under the knife: medical student perceptions of intimidation and mistreatment. J Surg Educ. 2015;72:749-53.

\section{EDITORIAL COMMENTARY}

\section{The view from the other side of the table: Beginning a practice in academic thoracic surgery}

\author{
David D. Odell, MD, MMSc \\ From the Division of Thoracic Surgery, Department of Surgery, Surgical Outcomes and Quality Improvement \\ Center, Center for Healthcare Studies, Institute for Public Health and Medicine, Northwestern University \\ Feinberg School of Medicine, Chicago, Ill. \\ Disclosures: Author has nothing to disclose with regard to commercial support. \\ Received for publication Jan 3, 2016; accepted for publication Jan 5, 2016; available ahead of print Feb 10, 2016. \\ Address for reprints: David D. Odell, MD, MMSc, Division of Thoracic Surgery, Surgical Outcomes and Quality \\ Improvement Center, Center for Healthcare Studies, Institute for Public Health and Medicine, Northwestern \\ University Feinberg School of Medicine, Chicago, IL (E-mail: dodell@nm.org). \\ J Thorac Cardiovasc Surg 2016;151:924-5 \\ $0022-5223 / \$ 36.00$ \\ Copyright (C) 2016 by The American Association for Thoracic Surgery \\ http://dx.doi.org/10.1016/j.jtcvs.2016.01.004
}

Perhaps the most challenging period most surgeons face in their lives is making the transition at the end of residency training into their first attending position. In many ways, entering practice may be more challenging now than ever before. New surgeons must navigate changing practice models that place increased emphasis on productivity and outcomes along with an expanding scope of practice driven by discovery and the advent of technology. In this issue of the Journal, Drs David and Nasir ${ }^{1}$ present their perspective on the transition from training into practice in academic general thoracic surgery and offer advice to surgeons preparing to begin their academic careers. Although David and Nasir ${ }^{1}$ focus on academic general thoracic surgery, several of the topics discussed are germane to all surgeons, such as strategies for dealing with complications early in one's career and developing a specialty niche to set oneself apart clinically. Because of their focus on academic surgery, however, a specific emphasis is placed on facets unique to this environment, such as striking a balance between research and clinical practice and the challenge of teaching residents to operate while still learning the nuances of independent surgery. David and Nasir ${ }^{1}$ create a framework in which some of the many issues surgeons face at the beginning of an academic practice may be discussed. The topics highlighted, however, represent only a sampling of the challenges inherent to the transition to practice. These

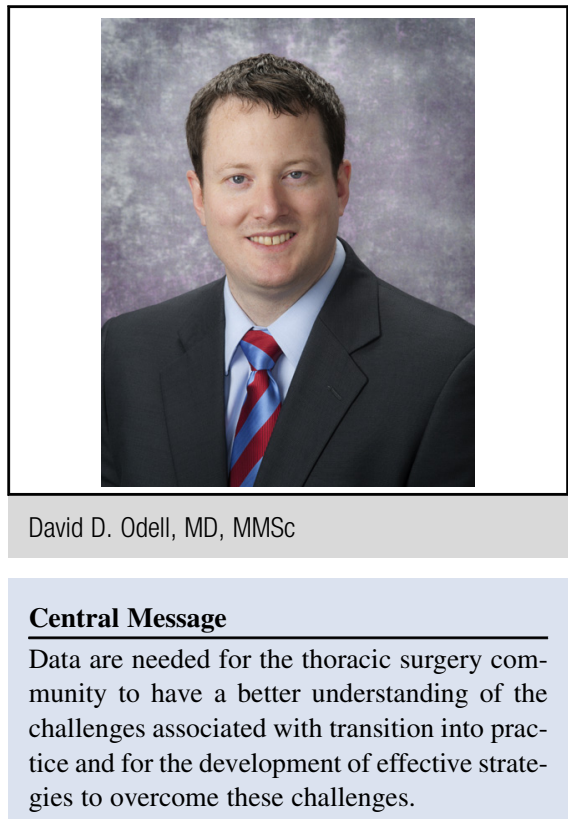

See Editorial page 920.

challenges are in fact unique for every surgeon as a function both of individual aptitudes and the environment in which the surgeon begins practice. As such, the advice provided by David and Nasir, ${ }^{1}$ although sound, may not be universally applicable. New surgeons, and those who hire and mentor them, should be encouraged to identify potential challenges specific to their own practice environments and to work together to address them proactively.

The ability to find adequate mentorship is perhaps the most important component in the success of an academic surgeon. David and Nasir ${ }^{1}$ touch on this topic, but it cannot be overemphasized. Navigating the transition to practice can be trying even in the best of circumstances, and seeking 